\title{
Turning Customer Insights CONTRIBUting To VMI Based Decision Support System in Demand Chain Management
}

\author{
Dr. T. G. K. Vasista \& Dr. A. M. AlAbdullatif \\ ${ }^{1}$ Deanship of e-Transactions and Communications, King Saud University, Riyadh, Saudi \\ Arabia
}

\begin{abstract}
Thus Demand chain management (DCM) is emerging as an innovative concept of managing the supply chain. A typical business analytic service is expected to sense trends and insights from data, then model 'what if' scenarios to support better decision-making from the insights derived. It should also be able to deliver short term strategic engagements consistently for long term managed services. Rather than focusing merely on supply chain concept as a forward chaining approach, Demand-chain as a backward chaining strategy initiatives focus on better ways to capture the demand signal close to the source, analyze the demand to sense the latest and most accurate demand signal and shape the demand by executing and tracking promotional and pricing strategies to steer demand in line with business objectives. VMI is an efficient replenishment practice designed to enable the vendor to respond to demand without the distortive effect of purchasing decisions in the retail chain. Therefore the objective of this paper is to focus on how to turn customer insights into Vendor-Managed Inventory based Decision Support System in Demand Chain Management especially with the support of state-of-the-art information communication systems and technologies. It concludes by saying that there is a need of adopting innovative management methodologies such as CRASP management methodology and the need of working on adding semantics to big data analytics based decision support system to enable semantic decision making capability to better derive and realize the strategic value of the business.
\end{abstract}

\section{KEYWORDS}

Big Data, CRASP methodology, Customer Insights, Decision Support Systems, Demand Chain Management, Semantic Decision Making, Vendor-Managed Inventory

\section{INTRODUCTION}

Vendor-managed inventory (VMI) is emerging as a significant development in recent trends towards collaboration, planning, forecasting, replenishment and information sharing in supply chain management. Competition arises because of brand substitution; i.e. some consumers may switch to another brand when their preferred brand is out of stock. Therefore when retailer makes the stocking-level decisions, the competitions are mitigated by pooling the demands at the retailer explicitly as in [1]. Manufacturers, or vendors and their customers continue to adopt vendor managed inventory programs to improve supply chain performance through collaboration achieved by consolidating forecasting and replenishment responsibility upstream with vendors. VMI works because vendors gain a better understanding of end-consumer demand and can fulfil this demand with a degree of focus that multi-category distributors and retailers cannot match. But there is a need of understanding the dynamics of customer demand to better drive the supply chain with VMI programs. In fact, VMI programs often degrade supply chain performance because vendors lack visibility on retailer-based information at the store-level events. This kind of visibility is needed to forecast demand accurately. Demand driven VMI leverages the proven, 
demand planning, inventory management, collaboration and promotion planning capabilities explicitly as in [2].

Thus Demand Chain Management (DCM) is emerging as an innovative concept of managing the supply chain. DCM is defined as the alignment of demand creation and its fulfilment process, which is considered as the driving force for effective and efficient functioning of collaborative supply chain. The goal of DCM is both to reduce and if possible eliminate buffers of inventory in the supply chain and at the same time delivering the customer demand explicitly as in [3].

A typical business analytic service is expected to sense trends and insights from data, then model 'what if' scenarios to support better decision-making from the insights derived. It should also be able to deliver short term strategic engagements consistently for long term managed services. SWOT analysis can be used to find the current opportunities. After identifying the opportunity, a right tactics is required to be chosen among many available such as: low price, service quality, promotional offers related to customer profitability to gain customer loyalty and satisfaction etc. There is a need to test and refine these tactics in the form of enabling predictive analytic programs in order to realize the business value or the associated customer life time value with the product/company/enterprise. Hence customer analytic service should be enabled, which include the following: (i) customer profiling, location and product segmentation development, (ii) category role identification and strategy development (iii) customer choice modelling and product feature/incremental analysis (iv) demand forecasting (v) root cause analysis (vi) Market Basket Analysis (MBA), association analysis, cross purchase loyalty and exclusivity analysis (vii) price, promotion, brand, portfolio/assortment, space and location optimization (viii) vendor performance (ix) Enterprise performance explicitly as in [4].

Demand-side initiatives focus on better ways to capture the demand signal close to the source, analyze the demand to sense the latest and most accurate demand signal and shape the demand by executing and tracking promotional and pricing strategies to steer demand in line with business objectives. The concept of demand driven supply chain is an important subject that contributes to problems \& issues related to mitigating bullwhip effect explicitly as in [5].

\section{OBJECTIVE}

Good relationship between the customer and supplier contributes to reliable information flows, and reliable demand information flows in turn contribute to high efficiency. But in a fastgrowing systems business such as mobile telecom industry, the supplier needs are required to be adaptable to its offering to a wide variety of customer situations and needs. Understanding the customers' situation and need together with the right offering contributes to good co-operation in improving the joint demand chain, which further leads to superior demand chain efficiency and high customer satisfaction explicitly as in [6]. Therefore the objective of this paper is to focus on how to turn customer insights into Vendor-Managed Inventory based Decision Support System in Demand Chain Management especially with the support of state-of-the-art information communication system and technologies.

\section{VENDOR MANAGED INVENTORY (VMI)}

VMI is an efficient replenishment practice designed to enable the vendor to respond to demand without the distortive effect of purchasing decisions in the retail chain explicitly as in [7]. Vendor Managed Inventory (VMI) systems have been initiated by certain manufacturers to improve both retail customer service levels and turnover. VMI systems achieve these goals through more accurate sales forecasting methods and more effective distribution of inventory in the supply chain [8]. 


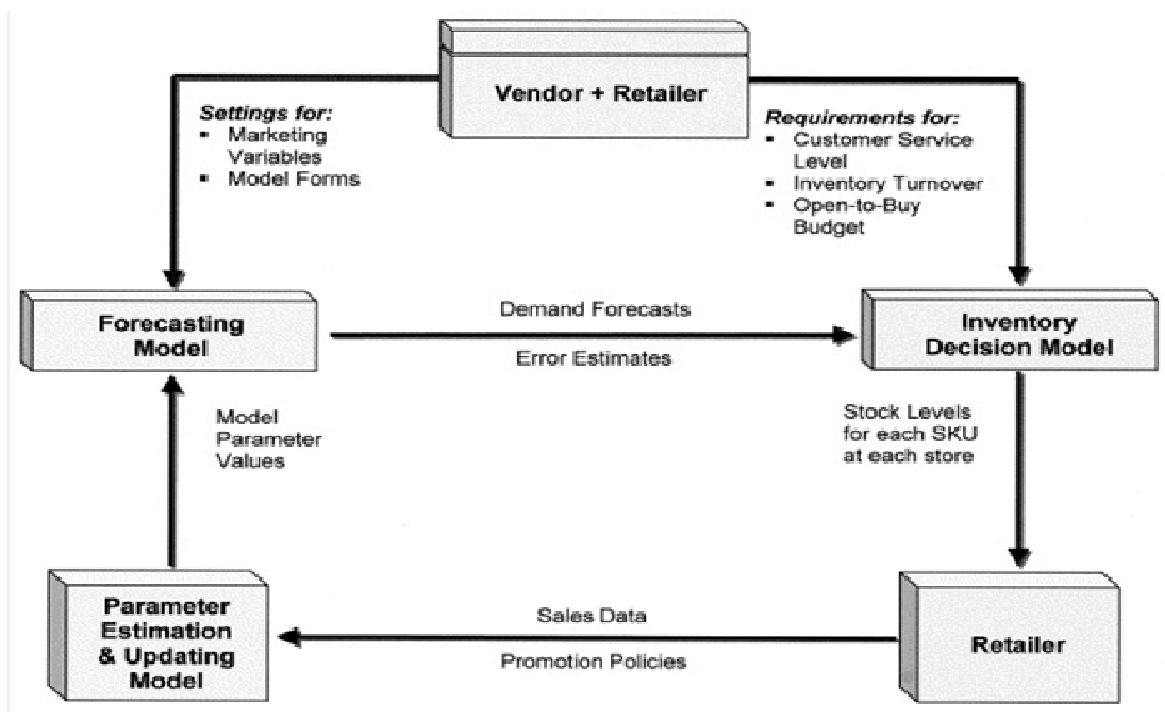

Figure 1. Model Used for VMI Decision Support System explicitly as in [8]

Although Collaborative, Planning, Forecasting and Replenishment (CPFR) systems can improve sales forecasts through information sharing between retailers and vendors, they may not lead to the same accuracy levels, which can be achieved through VMI. The coordination of inventory levels when the retail prices are fixed and development of models for the effects of VMI on service level as well as channel profits is an important study in VMI. Vendor may have a higher perceived cost of stock-outs than the retailers because a customer may simply substitute a different brand at the same store when a stock-out occurs explicitly as in [8].

\subsection{Benefits of VMI}

The following are the benefits of VMI as mentioned explicitly as in [8]:

To Retailers: (i) More effective inventory management, (ii) less uncertainty regarding inventory turnover, (iii) A cost effective way to obtain sales forecasting and inventory management services (iv) improved communication and relationship with retailers, (v) faster stock replenishment (vi) better customer retention (vii) less administrative burden for retailer (viii) enhanced retailer satisfaction.

To Vendors: (i) Increase the availability of their brand in stores relative to competitors' brands (ii) Increases customer loyalty in terms of making the customer priorities satisfied in terms of styles and colours of the product availability so that customer does not shift to similar products from competitor's brands, (iii) Avoids the affects of intentional inflation of product supplies by appropriately allocating the product supply share to the retailers as per the sales volume patterns conducting by retailers (i.e. possible to escape from the bullwhip effect) (iv) improved communication and relationship with suppliers (v) enhanced inventory turns (vi) cash-flow certainty for supplier (vii) less administrative burden for suppler (viii) enhanced supplier satisfaction.

The Bullwhip effect is a term coined by Lee et al. (1997) [9]. It refers to the scenario where the orders to the supplier tend to have larger fluctuations than sales to the buyers and the distortion propagates upstream in an amplified form. Five fundamental causes of bullwhip effect are: demand signal processing, non-zero lead times, price variations, rationing and gaming and order 
batching. The demand amplification or the Forrester Effect encompasses signal processing and non-zero lead times. It is possible that the customer Insights could be made contributing to VMI, which in turn show significant effect at responding to volatile changes in demand such as those due to discounted ordering or price variations. VMI can improve Inventory recovered as a measured by the integral of time $\mathrm{X}$ absolute error performance metric. VMI can be used to respond to random customer demand by measuring the noise band width i.e. a measure of capacity requirements to estimate the order rate variance (Bullwhip Effect) explicitly as in [10].

The Midway Truck Parts (a primary supplier to Midway, SKF), which is having alliance with SKF and Datalliance when adopted VMI has reaped the business benefits as follows: (i) stockouts are decreased 64 percent, product demand is increased by 32 percent, sales volume is increased by 10 percent in US Dollars, Inventory Turns are improved by 10 percent explicitly as in [11].

\subsection{Challenges in VMI}

Identifying the ownership as well as conforming the stakeholder in a typical dynamic supply chain network echelon is a challenging issue to deal with because of the dealings of the inclusion and exclusion of members dynamically into the network echelon become a more complex and challenging job. Thus viewing the proprietorship needs to be shifted to higher level than what has been considered with current level of proprietary information level explicitly as in [12]. There is a need of paradigm shift of viewing the structure from a monolithic sense to a next higher level of adaptable level abstraction. For example, a neutral term called 'customer' can be assigned to both retailer and supplier in view of bringing the abstraction level when brought to the customer level, a characteristic called 'adaptability' comes into the picture to deal with. Correspondingly new processes and jobs tasks, setting up terms related to new customizable metrics for different contexts is required to be established with electronic connections with different but generic supply chain partners in order to move the enterprise to the right strategic direction.

In order to address this challenge, AlSudairi \& Vasista (2014a) [13] designed and proposed a strategic methodology perspective for sustainable value chain management called CRASP (Customer-Respond-Adapt-Sense-Provider) Methodology. The core strength of this methodology lies in promoting the process level abstraction based on adopting the 'adaptability characteristic' within the work-flow along with semantic capability. Adaptability involves unbounded system thinking within the workflow. Workflow is a constituent component of a business system. A business system is usually domain-specific. At domain level, a workflow can be considered as a single (one) component but they reflect different at different business and organisational contexts or settings and also to a changing context. So adaptation inside a workflow may then need to take place to different contexts and at different levels. The taxonomy of adaptations levels could be: business context level, process level and resource level explicitly as in [14]. This is where the process level abstraction level has come into the existence to make the design adaptable, flexible yet agile.

\section{CRASP Management Methodology: A Methodology Directive}

Thus CRASP methodology is an adaptive enterprise model developed with agile systems thinking to address the issues and challenges by reflecting (social, economical and environmental factors) as a triple bottom line approach to sustainability. CRASP methodology based assessment offers a more comprehensive and holistic approach as it demands to adopt big data analytics based knowledge management approach and techniques in assessing sustainability measures and indicators towards achieving stakeholders' satisfaction by categorizing stakeholders into customers and providers explicitly as in [15]. 


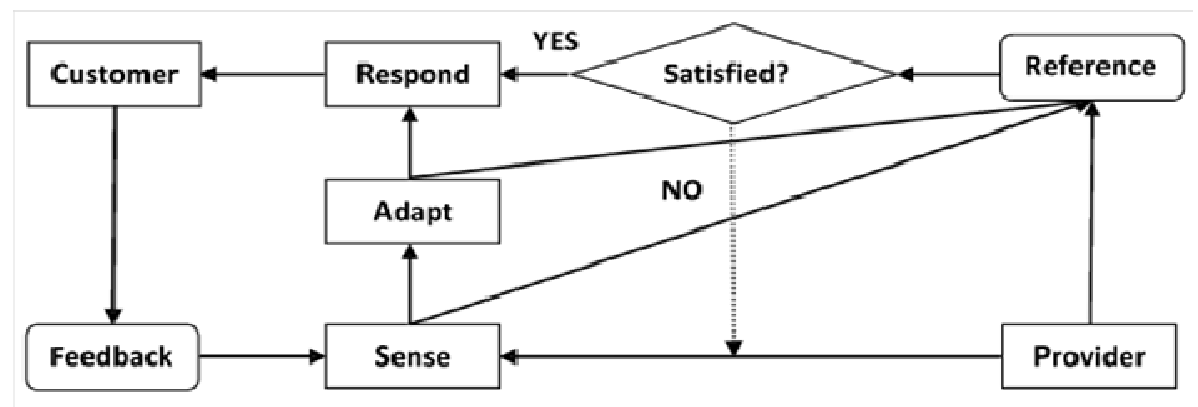

Figure 2. CRASP Strategic Management Methodology explicitly as in [13]

CRASP methodology can be adoptable to deal with Vendor Management Inventory Program. It is a kind of adopting demand chain management by considering specializations such as supply chain management, human resources management, marketing management, finance management and customer/corporate affairs into the integration aspect. CRASP methodology also refers to the holistic integrated view of enterprise performance, which uses knowledge management approach. The knowledge elicited out of knowledge management approach can be used as a reference, because it refers to several classification methods and approaches while building the knowledge that support consensus building. The classification of KM methods refers to memory based, system science based, context based, process based, ontology based and semantics based. But within the knowledge management approach, it has to develop the consensus building by sensing data and information from various sources and dynamics of the structure and its values in order to apply it to the context for adapting and adopting effective decision making practices explicitly as in [14].

\section{Towards Big Data Analytics}

In 21st century, Social Media Monitoring (SMM) tools are effectively delivering business benefits of impacting customer demand. These tools by monitoring are influencing online brand conversion and monitoring the buzz being created by the brand. Through CRM 2.0 kind of modern business practice SMM tools can capture the customer insights that can be derived from electronic word of mouth (eWOM) (e.g. email alerts, blog postings, comments in forums etc.) and viral marketing efforts. Company can use big data analytic tools to generate Ad-hoc reports, OLAP queries, data mining and predictive modelling based decision support programs in order enhance the certainty by adopting advance analytics and visualization tools such as dashboards. Thus management concepts such as VMI, CPFR, CRM, Category management etc. are integrated in one holistic approach to jointly develop customer affinity and loyalty. Therefore eWOM as a social mediated monitoring tools when combined with web analytics and predictive modelling will have potential to generate probabilistic information to upgrade its portfolio as an effective alternate to brand communication. In addition it is possible to make vendor consolidation and deal with customer demand fulfilment in a multi-enterprise collaboration based supply chain management scenario explicitly as in [16]. Demand information aggregation is considered as one of the important strategies for reducing bullwhip effect. This kind of information aggregation and sharing can influence supply chains and markets. The research conducted by Algharbat, Zamil \& Vasista (2015) [17] explicitly reveals that use of ERP software, Social Media Monitoring Software and Business Intelligence software, which can significantly influence in mitigating bullwhip effect.

Tesco and Walmart can be considered as two examples that are driving strategic decision of supply chain based on customer data analytics. As an example, The Tesco Company gathers huge amounts of customer data from its loyalty program. It then mines this data to inform 
International Journal of Managing Value and Supply Chains (IJMVSC) Vol. 6, No. 2, June 2015

decisions from promotions to strategic segmentation of customers. Amazon came early to the frontiers of data analytics. The online retailer used the predictive modelling technique to generate customer campaigns based on what is called collaborative filtering. Walmart was also early the adopter of data-driven supply chains. By making supply-and-demand signals visible between retail stores and suppliers, the company optimizes all its supply chain decisions-from customer fulfilment to inventory tracking (with EPOS data and RFID sensors) to automate purchase orders through its supplier portals explicitly as in [18].

Big Data is undergoing rapid resurgence as businesses across an increasingly diverse range of industrial sectors embrace large-scale data analytics to extract new, valuable insights from vast stockpiles of previously unmanageable data. Big Data analysis would extract insights and create new forms of value in ways that change markets, organisations and the relationship between citizens and governments. Inditex for instance, which own retail-chain Zara, collects data from its till receipts to identify demand for certain garments, and employs a just-in-time (JIT) production strategy to prevent the unwanted build-up of inventory. In general, companies throughout the globe are now witnessing a marked impact from the application of analytics and a range of retailers and manufacturers are already employing big data techniques to improve supply chain management and speedup the development of new products explicitly as in [19].

\section{BPM \& SOA SYNergy AND SEMANTIC MidDleware Technology: THE PRAGMATIC IMPLEMENTATION EQUIVALENT OF CRASP METHODOLOGY}

Process level mining can be adopted to derive the hidden trends for discovering new knowledge based on event logs. Most information systems that support structured data based business process management (e.g. ERP, CRM and workflow systems) record events in various forms such as transaction logs, audit trails and database tables. Process mining techniques use these event logs for all kinds of analysis based on labels attached to these logs. This means that these techniques cannot benefit from the actual semantics behind these labels which could cater for more accurate and robust analysis techniques. This kind of syntax oriented analysis technique results in spending more time on filtering, translating, interpreting and modifying event logs when given a specific question. Therefore endorsing the role of ontologies (and reasoners) while executing semantic analysis becomes important to use it as an extension to OLAP tools with semantics. Three important blocks in enabling semantic process mining conceptually could be: (i) SA-MXML i.e. Semantically Annotated Mining eXtensible Markup Language, (ii) Web Service Markup Language (WSML) to Reasoner Framework (because ontologies are defined in WSML) and (iii) a conformance analysis plug-in called Semantic Linear Temporal Logic (LTL) checker so as to verify properties defined in terms of LTL. The purpose of ontology building is to capture the taxonomies of semantics so that Business Process Intelligence tool can be built as mentioned explicitly in [20].

Semantic models enable users to ask questions of the information in a natural way and help to identify patterns and trends in this information and discover relationships between disparate pieces of information. Process Orientation, Service Oriented Architecture and Ontology plays important role in semantic models. This kind of semantic models when integrated with Business Intelligence capability will have the potential to handle the adaptation and presentation of BI capability as well as the dynamic capability of integration through orchestration explicitly as in [21].

For example, Sell, Cabral, Motta, Domingue \& Pacheco (2005) [22] have presented an architecture that adds semantics to Business Intelligence called OntoDSS, which is a prototype tool as shown in figure 3 . 
Thus Business Intelligence Ontology building will have the capability to support the exploration of data sources as structured in Data Warehouse to address the range of abstraction levels as mentioned in ASCP model including the personalization of the presentation in passing [23] according to user's profile so that users receive suggestions of relevant filters, relations and services for the purpose of enabling different perspective of an analysis explicitly as in [22].

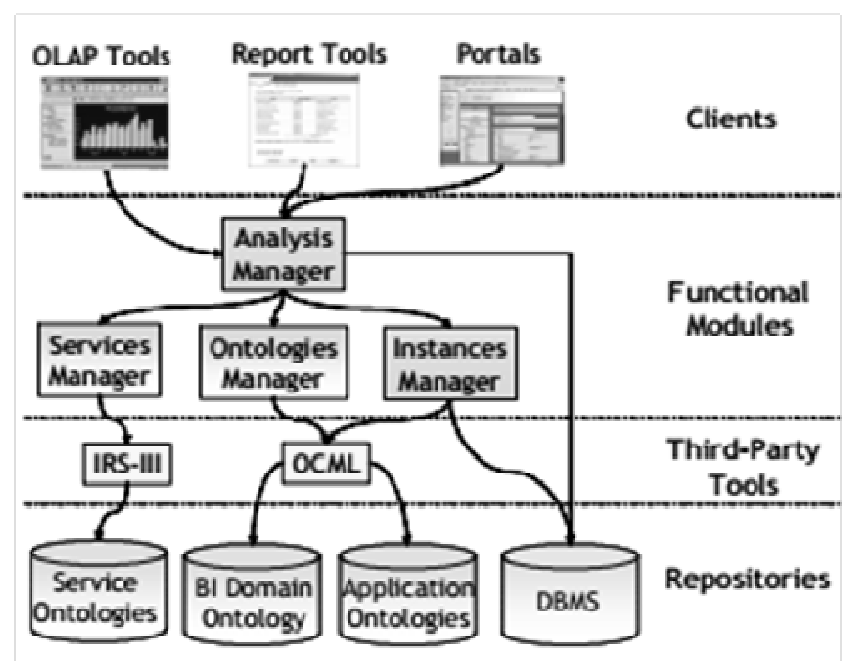

Figure 3. OntoDSS explicitly as in [22]

Further, Vasista. (2013) [24] explicitly suggested the need of decision making ontology models of representation of control, both at process level and meta-model level, based on the review of the research conducted by Bargui et al. (2011) in passing [25] and also suggested a macro level socio-economic performance based sustainability conceptual framework sourced from Pollitt \& Bouchaert (2011) in passing [26].

\section{DISCUSSION \& CONCLUSION}

IT spending is increasingly dominating corporate investment spending. For example, 32 percent in 35 percent of IT spending of corporate investment was in software during the year 1990 was increased to 60 percent out of 47 percent of IT spending of corporate investment. These kind of technology-based transformation systems have positive influence on five areas of business viz.: (i) customer experience (ii) process effectiveness (iii) business integration (iv) data and information and (v) introducing new/innovative products and services as mentioned explicitly in [27, p. 9 \&11]. Based on the Exhibit 3 in passing [27, p. 11] the traditional management methodologies that have been currently in use might require undergoing a paradigm shift in their approach by adopting CRASP strategic management methodology especially when dealing with business as technology driven business or when dealing with digital business technologies. It is because CRASP methodology is an adaptive enterprise model developed with agile systems thinking to address the issues and challenges arising in demand chain management. In this article it is proposed that it is important to view the strategic value of business not just merely from interpretations derived out of operational based data analysis perspectives but from considering and keeping the positional value of strategy at the absolute level for which there is a need of generating the components related to ontology, verifiers and reasoners. Hence generating such kind of components and encapsulating such knowledge through the technology and applying it to elicit business decision support patterns and trends become a challenge to the community and industry of technology driven business and business driven technology. 
International Journal of Managing Value and Supply Chains (IJMVSC) Vol. 6, No. 2, June 2015

\section{REFERENCES}

[1] Mishra, B. K. \& Raghunatha, S. (2004). "Retailer- vs. Vendor-managed Inventory and Brand Competition", Management Science, Vol. 50, No. 4, pp 445-457.

[2] Oracle (2006). "A Demand-Driven Approach to Vendor Managed Inventory". [Online URL: http://www.oracle.com/us/products/applications/ebusiness/scm/062108.pdf (Accessed May 11, 2015).

[3] Madhani, P. M. (2013). Demand Chain Management: Enhancing Customer Value Proposition. [Online] URL: http://www.europeanbusinessreview.com/?p=1945 (Accessed on May 11, 2015).

[4] Accenture Customer Insight (2013). "Creating Value through Actionable Customer Intelligence. Accenture Interactive". [Online] URL: http://www.accenture.com/sitecollectiondocuments/pdf/accenture-customer-insights-v2.pdf (Accessed on May 10, 2015).

[5] Lipton, M. (2013). "Demand-Driven Supply Chains are in Demand". [Online] URL: http://www.industryweek.com/supplier-relationships/demand-driven-supply-chains-are-demand (Accessed on May 11, 2015).

[6] Heikkila, J. (2002). "From Supply to demand chain management: efficiency and customer satisfaction", Journal of Operations Management, Vol. 20, No. 6, pp. 747-767.

[7] Holmstrom, J. (1998). "Business process innovation in the supply chain - a case study of implementing vendor managed inventory". European Journal of Purchasing \& Supply Chain Management. Vol. 4, pp. 127-131.

[8] Achabal, D., McIntyre, S. H., Smith, S.A., Kalyanam, K. (2000). "A decision support system for vendor managed inventory”, Journal of Retailing. 76(4), 430-454.

[9] Lee, H. L., Padmanabhan, V. \& Whang, S. (1997). "The Bullwhip Effect in Supply Chains", MIT Sloan Management Review. Vol. 38, No. 3, pp. 93-102.

[10] Disney, S. M. \& Towill, D. R. (2003). "The effect of vendor managed inventory (VMI) dynamics on the Bullwhip Effect in supply chains". International Journal of Production Economics. Vol. 85, No. 2, pp. 199-215.

[11] Datalliance (Undated). "Midway Truck Parts Improves Business Results and Supplier Relationship with [Online] URL", http://www.hdexchange.com/Midway_Success_Story.pdf (Accessed on May 11, 2015).

[12] Kellogs Business School (Undated). "Vendor Managed Inventory". [Online] URL: http://www.prenhall.com/divisions/bp/app/chopra/word/vmi.doc (Accessed on May 10, 2015).

[13] AlSudairi, M. A. T \& Vasista, T. G. K. (2014a). "CRASP - A Strategic Methodology Perspective for Sustainable Value Chain Management”. In Proceedings of 23rd IBIMA Conference, 13-14 May, Valencia, Spain

[14] AlSudairi, M. A. T \& Vasista, T. G. K. (2014b). "A Comprehensive Description of advantages of adopting CRASP: the Agile \& Cloud based Strategic Methodology". Unpublished Paper Developed at King Saud University, Riyadh, KSA.

[15] AlSudairi, M. A. T., Freeland, A. \& Vasista, T. G. K (2015). "Enterprise Business Value Assessment Grid: An Enterprise Approach to Reduce the Business Relation Gap between Business Provider and Business Requester using Cloud Big Data Technology through Enterprise Strategic Management". Unpublished Paper Developed at King Saud University, Riyadh, KSA.

[16] AlSudairi, M. A. T. \& Vasista, T. G. K. (2012). "Mitigating the Bullwhip Effect with eWord of Mouth: eBusiness Intelligence Perspective". International Journal of Managing Value and Supply Chains (IJMVSC) Vol. 3, No. 4, pp. 27-41.

[17] Algharbat, R. S., Zamil, A. M. A. \& Vasista, T. G. K. (2015). "The Influence of Retailer Enterprise Marketing Information System on Bullwhip Effect”. International Journal of Business and Management. Vol. 10, No. 3, pp. 237-248.

[18] Sanders, N. (2014). "Big Data Driven Supply Chain Management: A framework for implementing analytics and tuning information into intelligence". [Online] URL: http://www.ftpress.com/store/big-data-driven-supply-chain-management-a-framework-

9780133801286?w_ptgrevartcl=Big+Data+Driven+Supply+Chain+Management\%3a+A+Game+ Changer_2218298 (Accessed May 2014).

[19] Euroasiaindustry (2014). Extracting Insight. [Online] URL: http://www.euroasiaindustry.com/article/extracting-insight (Accessed on May 11, 2015).

[20] de Medeiros, A.K. A, van der Aalst, W. \& Pedrinaci, C. (2008). Semantic process mining tools. In 16th European Conference on Information Systems, 9-11, Galway, Ireland. [Online] URL: 
http://oro.open.ac.uk/23397/1/TowardsSemanticProcessMiningTool-ECIS2008.pdf (Accessed on May 10, 2015).

[21] AlSudairi, M. A. T. \& Vasista, T. G. K. (2013a). "Knowledge on demand approach using Business Intelligence and Ontology". Unpublished Paper, King Saud University, Riyadh, KSA. [Online]

URL: https://www.academia.edu/3458783/Knowledge_on_demand_approach_using_Business_Intellige nce_and_Ontology (Accessed on May 10, 2015).

[22] Sell, D., Cabral, L., Motta, E., Domingue, J. \& Pacheco, R. (2005). "Adding Semantics to Business Intelligence”. In DEXA Workshops, Las Alamitos, 543-547, IEEE Computer Society Press.

[23] AlSudairi, M. A. T. \& Vasista, T. G. K. (2013b), "Achieving Process Standardization in Digital Society with 'ASCP Model'”. Journal of Supply Chain \& Customer Relationship Management, Article ID 759359, pp. 1-12.

[24] Vasista, T. G. K. (2013). System, Spiritual and Philosophical Perspectives of Human Life and the Role of Governance in a Socio-Economic Setting. Unpublished Paper Developed at King Saud University, Riyadh, KSA.

[25] Bargui, F., Ben-Abdullah, H., \& Feki, J. (2011). A decision making ontology building process for analytical requirement elicitation. International Joint Conference of IEEE TrustComm-11, IEEE ICESS-11 and FCST-11, IEEE Computer Society.

[26] Pollitt, C. \& Bouchaert, G. (2011). Public Management Reform: A comprehensive analysis new public management, governance and the neo-weberian state, 3rd Edition, Oxford University Press.

[27] McKinsey-CBT (2012). Perspectives on Digital Business. McKinsey Centre for Business Technology. [Online] URL: http://www.springer.com/cda/content/document/cda_downloaddocument/9783642317644c2.pdf?SGWID=0-0-45-1344851-p174540940 (Accessed on May 11, 2015)

\section{Authors}

Dr. TGK Vasista is currently associated with Deanship of E-Transactions and Communications at King Saud University, Riyadh, Saudi Arabia. He obtained a Doctorate in Information Technology from Commonwealth of Dominica, West Indies, a Post-Graduate Diploma in E-Governance from India, an MBA in EBusiness from USA and a Master of Engineering in Civil Computer Aided Design from India. He has former experiences in the field of IT as a programmer analyst in USA and as a senior Lecturer/Asst. Professor in academic field in the area of Systems and IT, E-Business and E-Governance. His interested areas include: EBusiness, E-Governance and Enterprise Systems. He has about 50+ publications related to E-business and E-governance overall, which include some in refereed journals and both international and national conferences. He received a best paper award in a National IT conference in 2007 in India.

Dr. A. M. AlAbdullatif is currently the Vice-Dean for e-Services and Projects at Deanship of E-Transactions and Communications at King Saud University, Riyadh, Saudi Arabia. He obtained a Doctor of Philosophy from Heriot-Watt University, UK and a Master of Science in Computer Science from Edinburgh University, UK. He also worked as a faculty of computer science in King Saud University, Riyadh. He has few publications in refereed journals and international conferences. His interested areas of

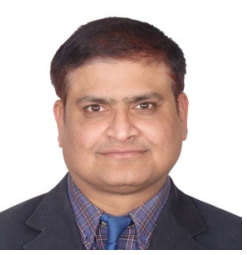
research include: Performance Engineering and E-Services.

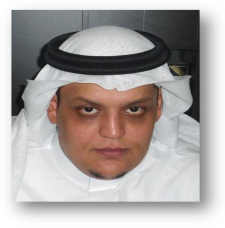

